\title{
AMENDMENTS
}

\section{Author Correction: Experimental evidence for sustained carbon sequestration in fire-managed, peat moorlands}

\author{
R. H. Marrs (D), E.-L. Marsland, R. Lingard, P. G. Appleby, G. T. Piliposyan, R. J. Rose, J. O'Reilly, G. Milligan, K. A. Allen, \\ J. G. Alday $\mathbb{D}$, V. Santana, H. Lee $\mathbb{D}$, K. Halsall and R. C. Chiverrell $\mathbb{D}$
}

Correction to: Nature Geoscience https://doi.org/10.1038/s41561-018-0266-6, published online 3 December 2018.

In the version of this Article originally published, the authors neglected to include information on Competing Interests. The below has now been included in all versions of the Article.

Financial competing interests: The work reported in this paper was 95\% funded by a Biodiversa grant (ERA-net project within the European Union's 6th Framework Programme for Research - 2008 Joint call), which in the UK was funded jointly by DEFRA/NERC (NE/G002096/1). DEFRA is a government ministry whose policy is not to burn on peat. R.H.M. was a co-Investigator. The other 5\% (about $£ 2,000$ ) was provided by the Heather Trust, which is a charity dedicated to moorland and upland environment management.

Non-financial competing interests: R.H.M. is a member of the Heather Trust and currently their honorary President; in this role he is specifically barred from interfering in any aspect of their work and does not have voting rights. The Trust aims to provide good moorland management and foster peat conservation in a range of different ways, of which burning is one approach. The Heather Trust does not seek to influence the author's views when work they support is published. R.H.M. was an expert panel member for DEFRA in 2004 and 2005, when the regulations for burning on peatland were re-written. R.H.M. was an expert witness in a public inquiry on Heather Burning in 2012, supporting a private client. R.H.M. was an author of two of the reports by the IUCN UK Peatland Programme's Commission of Inquiry on Peatlands. R.H.M. is a member of the Game Conservancy \& Wildlife Trust's Uplands Research Committee; this is advisory only and is unpaid. R.H.M. is not a member of the GWCT, is not involved with game shooting in any way, has never shot game of any description and has never attended any game-shooting event.

Published online: 10 January 2019

https://doi.org/10.1038/s41561-019-0303-0

\section{Author Correction: World's landlocked basins drying}

Tamlin M. Pavelsky

Correction to: Nature Geoscience https://doi.org/10.1038/s41561-018-0269-3, published online 30 November 2018.

In the version of this News \& Views originally published, the lead author of ref. 3 was incorrectly referred to as 'Yang' in the main text; the correct surname is 'Wang. This has now been corrected in the online versions.

Published online: 12 December 2018

https://doi.org/10.1038/s41561-018-0289-Z

\section{Author Correction: Anthropogenic stresses on the world's big rivers}

Jim Best

Correction to: Nature Geoscience https://doi.org/10.1038/s41561-018-0262-x, published online17 December 2018.

In the version of this Review originally published, the author name 'Arthington' was misspelt in refs 216 and 218 . Further, in the sentence that starts "Global warming has also been linked to potentially significant increases in the flow of Russia's three great Artic rivers..., 'Artic' should have been 'Arctic'. These errors have now been corrected. 